\title{
Hepatitis E Virus Genotypes and Evolution: Emergence of Camel Hepatitis E Variants
}

\author{
Siddharth Sridhar ${ }^{1}$, Jade L. L. Teng ${ }^{1,2,3,4}$, Tsz-Ho Chiu ${ }^{1}$, Susanna K. P. Lau ${ }^{1,2,3,4}$ \\ and Patrick C. Y. Woo 1,2,3,4,* \\ 1 Department of Microbiology, Li Ka Shing Faculty of Medicine, The University of Hong Kong, \\ Hong Kong, China; sid8998@gmail.com (S.S.); llteng@hku.hk (J.L.L.T.); \\ tsz.chiu@uqconnect.edu.au (T.-H.C.); skplau@hku.hk (S.K.P.L.) \\ 2 State Key Laboratory of Emerging Infectious Diseases, Department of Microbiology, \\ Li Ka Shing Faculty of Medicine, The University of Hong Kong, University Pathology Building, \\ Queen Mary Hospital, Hong Kong, China \\ 3 Research Centre of Infection and Immunology, Li Ka Shing Faculty of Medicine, \\ The University of Hong Kong, Hong Kong, China \\ 4 Carol Yu Centre for Infection, Li Ka Shing Faculty of Medicine, The University of Hong Kong, \\ Hong Kong, China \\ * Correspondence: pcywoo@hku.hk; Tel.: +852-22-554-892; Fax: +852-28-551-241
}

Academic Editor: Johannes Haybaeck

Received: 27 March 2017; Accepted: 18 April 2017; Published: 20 April 2017

\begin{abstract}
Hepatitis E virus (HEV) is a major cause of viral hepatitis globally. Zoonotic HEV is an important cause of chronic hepatitis in immunocompromised patients. The rapid identification of novel HEV variants and accumulating sequence information has prompted significant changes in taxonomy of the family Hepeviridae. This family includes two genera: Orthohepevirus, which infects terrestrial vertebrates, and Piscihepevirus, which infects fish. Within Orthohepevirus, there are four species, A-D, with widely differing host range. Orthohepevirus A contains the HEV variants infecting humans and its significance continues to expand with new clinical information. We now recognize eight genotypes within Orthohepevirus A: HEV1 and HEV2, restricted to humans; HEV3, which circulates among humans, swine, rabbits, deer and mongooses; HEV4, which circulates between humans and swine; HEV5 and HEV6, which are found in wild boars; and HEV7 and HEV8, which were recently identified in dromedary and Bactrian camels, respectively. HEV7 is an example of a novel genotype that was found to have significance to human health shortly after discovery. In this review, we summarize recent developments in HEV molecular taxonomy, epidemiology and evolution and describe the discovery of novel camel HEV genotypes as an illustrative example of the changes in this field.
\end{abstract}

Keywords: hepatitis E; zoonosis; hepatitis; taxonomy; molecular evolution; molecular epidemiology; genotypes; dromedary camel; Bactrian camel; swine

\section{Introduction}

Hepatitis E virus (HEV) is an important cause of both epidemic and sporadic viral hepatitis. HEV has been estimated to cause 3.3 million symptomatic cases of acute hepatitis worldwide [1] and in some areas has overtaken hepatitis A as the most common cause of acute viral hepatitis [2]. Although most cases are self-limiting, pregnant women, in particular, have a propensity to progress to fulminant hepatitis [3]. Furthermore, immunocompromised patients such as transplant recipients, patients with hematological malignancies and advanced HIV may progress to chronic hepatitis following an HEV infection [4-6]. 
The global distribution of human disease due to HEV relies partly on its "two-faced" epidemiology. In hyperendemic areas, hepatitis $\mathrm{E}$ is often linked to contamination of water supplies with human fecal material and represents person-to-person transmission [7]. However, in low endemic areas with high socioeconomic development, hepatitis $\mathrm{E}$ is predominantly a foodborne zoonosis, which is most commonly transmitted to humans consuming undercooked pork products $[7,8]$. In addition to pork, hepatitis $\mathrm{E}$ has also been transmitted to humans consuming meat or milk of feral animals including wild boar, deer, rabbits and camels [9-13].

The basis for this contrasting epidemiology lies in the phylogenetic diversity of HEV. Our knowledge of HEV diversity is constantly evolving with the discovery of novel HEV variants in various animal hosts around the world. With the accumulation of high-quality genomic information, HEV taxonomy has undergone significant changes recently to reflect the diversity of this family of viruses. Sophisticated sequence analyses have been possible to address various questions related to the molecular epidemiology and evolution of HEV. The objective of this review is to provide an update on the molecular basis of modern HEV taxonomy along with a summary of recent advances in HEV epidemiology and evolution. The discovery of camelid HEV genotypes and recognition of their importance to human health is used as an illustrative example of recent changes in this field.

\section{HEV Genomic Organization}

HEV is a nonenveloped virus with a $27-34 \mathrm{~nm}, T=1$ icosahedral capsid enclosing the viral genome. The single-stranded, positive-sense RNA genome varies from 6.6 to $7.3 \mathrm{kB}$ in length; similar to eukaryotic mRNA, the $5^{\prime}$ end has a 7 -methylguanylate $\left(\mathrm{m}^{7} \mathrm{G}\right)$ cap while the $3^{\prime}$ end is polyadenylated [14]. Short untranslated regions flank three open reading frames (ORFs), which are named ORF1, ORF2 and ORF3 in a $5^{\prime} \rightarrow 3^{\prime}$ direction. Overlapping reading frames ORF2 and ORF3 encode for frameshifted products from a bicistronic subgenomic mRNA species [15]. There is inter-species variation in the location of the ORF2/ORF3 junction with the divergent variant cutthroat trout virus having an ORF3 that is displaced towards the middle of ORF2 (Figure 1).

ORF1 is the longest of the three reading frames, accounting for nearly two-thirds of the entire genome [14]. It encodes a non-structural polyprotein that possesses several functional domains critical for viral replication [16]. There is still controversy regarding whether the ORF1 product undergoes any post-translational proteolytic processing [17]. Functionally characterized domains of ORF1 include a methyltransferase, helicase and RNA-dependent RNA polymerase (RdRp). Computational analysis of ORF1 also reveals a papain-like cysteine protease, macro and hypervariable domains. The exact role of these domains in the HEV replication cycle remains speculative and may indirectly be inferred by homologous domains in other positive-sense RNA viruses [16].

The ORF2 region on the $2.2 \mathrm{kB} \mathrm{m}^{7} \mathrm{G}$ capped subgenomic RNA (sgRNA) species encodes the viral capsid protein, which is important for viral entry and also contains immunological epitopes for antibody targets [17]. The ORF3 region is also expressed from the same sgRNA species and the start codons of ORF2 and ORF3 are only separated by only a few nucleotides [14]. The ORF3 encoded phosphoprotein has been observed to interact with the cellular cytoskeleton and endosomal system and is tentatively believed to play a role in viral egress $[18,19]$. 


\begin{tabular}{|l|l|}
\hline ORF2 & 2 \\
\hline ORF3 & 3
\end{tabular}

HEV-4, HEV-5, HEV-6, HEV-7 (DcHEV-178C)

\begin{tabular}{|c|l|}
\hline ORF1 & ORF3 \\
\hline & ORF2 \\
\hline
\end{tabular}

Rat HEV

\begin{tabular}{|c|c|}
\hline ORF1 & ORF2 \\
\hline ORF3 & \\
\hline
\end{tabular}

Ferret HEV

\begin{tabular}{|c|c|c|}
\hline ORF1 & \\
\hline ORFF 2 \\
\hline
\end{tabular}

Bat HEV

\begin{tabular}{|c|c|}
\hline ORF1 ORF2 & OR2 \\
\hline
\end{tabular}

Avian HEV

ORF1

Cutthroas trout HEV

Figure 1. Predicted genomic organization of HEV-1 to HEV-8, considering the reading frame of ORF1 as frame 1. Reading frames of ORF2 and ORF3 are labeled relative to ORF1 reading frame. HEV-1 (M73218); HEV-2 (M74506); HEV-3 (AP003430); HEV-4 (AJ272108); HEV-5 (AB573435); HEV-6 (AB602441); HEV-7 strain DcHEV-178C (KJ496143); HEV-7 strain DcHEV-180C (KJ496144), HEV-8 (KX387865).

\section{Hepatitis E Virus (HEV) Taxonomy: In Constant Evolution}

HEV is difficult to culture from clinical specimens, animal models are not widely available and several HEV variants from diverse epidemiological sources appear to have broadly cross-reactive antigenicity [20-23]. Therefore, from an early stage, the genetic characteristics of HEV variants were the main basis for taxonomic classification as opposed to other viral families where serotyping and cell culture characteristics played an important role in early classification schema. Classifications of HEV using genetic methods also closely mirror ecology and zooepidemiology of virus variants proving the fundamental soundness of this technique. However, as more sequence information from divergent isolates became available, there was considerable confusion due to the proliferation of 
differing classification schemes based on methods such as nucleotide identities, genetic distances, amino acid identities, phylogenetic analysis, PCR-restriction fragment length polymorphism, and ORF structure of different areas of the genome [24-31]. Indeed, the very definition of various taxons within Hepeviridae has undergone continuous evolution to reflect the emerging diversity of the family.

Originally included as a member of the family Caliciviridae, HEV was reassigned to the newly-created family Hepeviridae in 2009 by the International Committee on Taxonomy of Viruses (ICTV). According to the current taxonomy release (2015), the family Hepeviridae includes two genera: Orthohepevirus and Piscihepevirus [32]. The former encompasses all mammalian and avian HEV variants while the latter includes the highly divergent cutthroat trout virus placed within a single species. The Orthohepevirus genus is further subdivided into four species (A-D). The current consensus proposals for classification of the family Hepeviridae adopted by ICTV were put forward by Smith et al. in 2014 [27,32].

Division of the family into the two aforementioned genera was made straightforward by the clear genetic differences of Piscihepevirus A, the sole species within the Piscihepevirus genus, from other HEV belonging to the Orthohepevirus genus: ORF3 of cutthroat trout virus (the only virus within the Piscihepevirus genus so far) is displaced far towards the middle of ORF2 (Figure 1) compared to members of the Orthohepevirus genus, and comparative inter-genus $p$-distances of even functionally significant (i.e., highly conserved) amino acid sequences encoded by ORF1 like methyltrasferase, helicase and polymerase exceed $0.55[27,33]$. Furthermore, overall sequence identities of ORF2 and ORF3 between cutthroat trout virus and other members of the Hepeviridae family are only $18-21 \%$ and $13-16 \%$, respectively. In comparison, amino acid sequence similarities of ORF2 and ORF3 between avian and mammalian HEV in the Orthohepevirus genus are $42-55 \%$ and $20-29 \%$, respectively [27]. Table 1 also illustrates other differences in genomic organization between cutthroat trout virus and other HEV types with reference to the newly discovered HEV8 camelid genotype. This extreme phylogenetic divergence is reflected in the ecology of Piscihepevirus, which infects fish, in contrast to other members of the family Hepeviridae, which infect terrestrial vertebrates.

Table 1. Comparison of nucleotide and deduced amino acid sequence identities of the most recently discovered genotype, HEV-8 (BcHEV-48XJ), and other genotypes of HEV*.

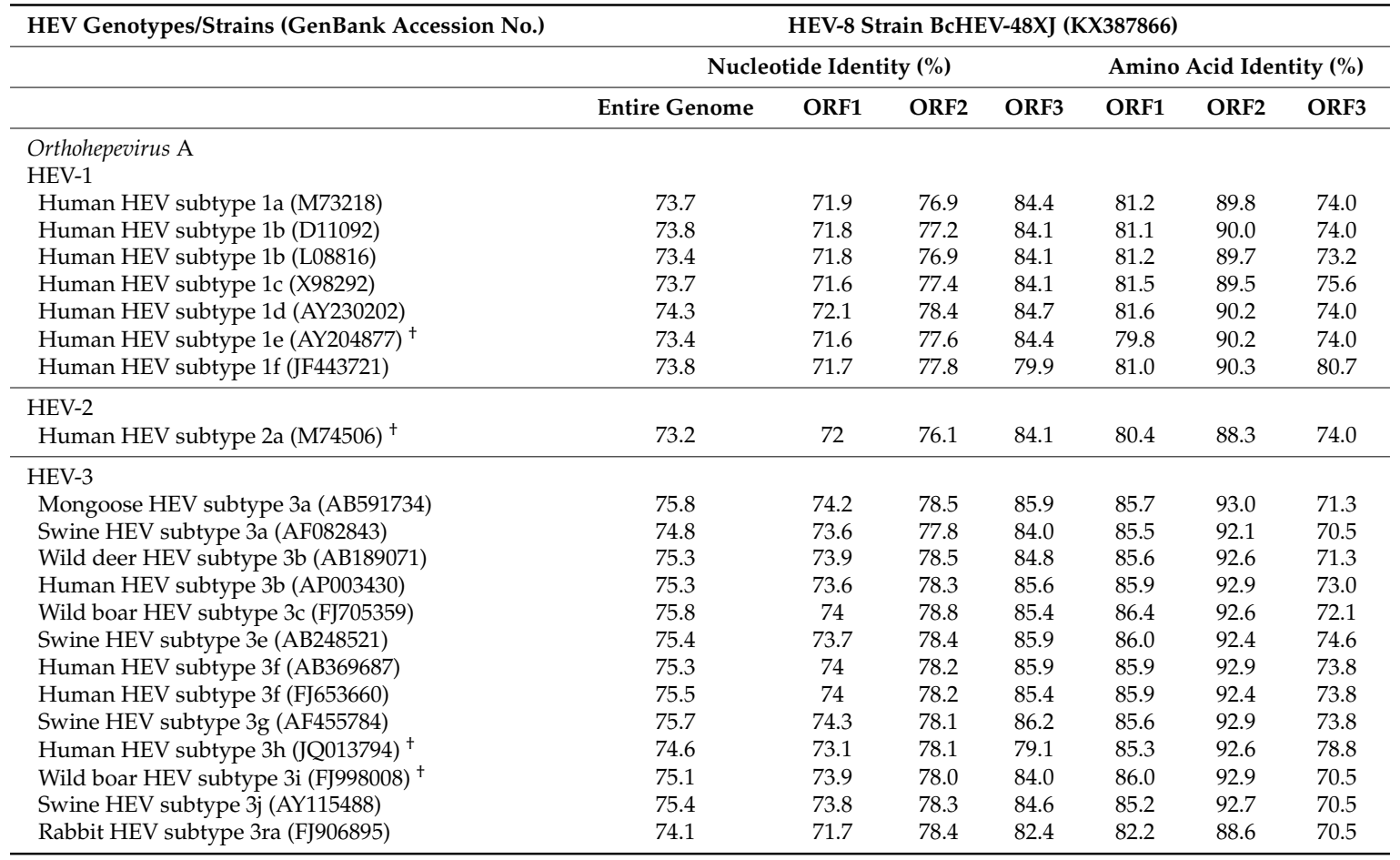


Table 1. Cont.

\begin{tabular}{|c|c|c|c|c|c|c|c|}
\hline \multirow[t]{3}{*}{ HEV Genotypes/Strains (GenBank Accession No.) } & \multicolumn{7}{|c|}{ HEV-8 Strain BcHEV-48XJ (KX387866) } \\
\hline & \multicolumn{4}{|c|}{ Nucleotide Identity (\%) } & \multicolumn{3}{|c|}{ Amino Acid Identity (\%) } \\
\hline & Entire Genome & ORF1 & ORF2 & ORF3 & ORF1 & ORF2 & ORF3 \\
\hline \multicolumn{8}{|l|}{ HEV-4 } \\
\hline Human HEV subtype 4a (AB197673) & 74.7 & 72.7 & 79.5 & 79.7 & 83.5 & 91.1 & 75.4 \\
\hline Swine HEV subtype 4b (DQ279091) & 74.8 & 72.4 & 80.4 & 80.2 & 83.4 & 90.7 & 74.6 \\
\hline Human HEV subtype 4c (AB074915) & 75.4 & 73.3 & 81.1 & 79.7 & 83.6 & 90.5 & 75.4 \\
\hline Human HEV subtype 4d (AJ272108) & 75 & 73.2 & 79.3 & 77.5 & 83.6 & 88.9 & 70.2 \\
\hline Swine HEV subtype 4e (AY723745) & 75.8 & 73.7 & 80.7 & 81.3 & 83.4 & 91.4 & 74.6 \\
\hline Human HEV subtype 4f (AB220974) & 75.2 & 73.1 & 80.3 & 81.8 & 83.4 & 90.7 & 77.2 \\
\hline Human HEV subtype 4g (AB108537) & 75.3 & 73.5 & 81.3 & 81.3 & 84.2 & 90.8 & 76.3 \\
\hline Swine HEV subtype 4h (GU119961) & 75.2 & 73.1 & 79.9 & 79.9 & 82.7 & 90.1 & 76.3 \\
\hline Swine HEV subtype 4i (DQ450072) & 75.5 & 73.2 & 80.0 & 87.0 & 82.7 & 92.4 & 73.0 \\
\hline \multicolumn{8}{|l|}{ HEV-5 } \\
\hline Wild boar HEV subtype 5a (AB573435) & 74.4 & 72.4 & 79.4 & 75.3 & 82.1 & 87.8 & 72.6 \\
\hline \multicolumn{8}{|l|}{ HEV-6 } \\
\hline Wild boar HEV 6 (AB856243) & 74.1 & 72.1 & 78.1 & 77.8 & 82.0 & 90.3 & 75.2 \\
\hline Wild boar HEV subtype 6a (AB602441) & 74.5 & 73.2 & 76.5 & 77.5 & 81.3 & 89.8 & 73.7 \\
\hline \multicolumn{8}{|l|}{ HEV-7 } \\
\hline DcHEV 7 (KJ496144) & 75.9 & 74 & 79.1 & 81.3 & 85.9 & 91.4 & 83.2 \\
\hline Human HEV $7\left(\right.$ KT818608) ${ }^{+}$ & 73.4 & 74.5 & 69.2 & NA & 85.9 & 82.1 & NA \\
\hline DcHEV subtype 7a (KJ496143) & 75.6 & 73.8 & 78.8 & 81.0 & 85.5 & 91.2 & 84.1 \\
\hline \multicolumn{8}{|l|}{ HEV-8 } \\
\hline BcHEV-62XJ (KX387867) & 98.3 & 98.2 & 98.8 & 99.7 & 98.8 & 99.7 & 100.0 \\
\hline BcHEV-12XJ (KX387865) & 96.3 & 96.1 & 97.0 & 97.8 & 98.0 & 99.2 & 99.1 \\
\hline \multicolumn{8}{|l|}{ Orthohepevirus B } \\
\hline Avian HEV genotype 2 (AY535004) & 52.9 & 52.8 & 51.6 & 42.3 & 43.2 & 44.8 & 24.8 \\
\hline \multicolumn{8}{|l|}{ Orthohepevirus C } \\
\hline Germany rat HEV (GU345042) & 57.1 & 56 & 59.9 & 54.2 & 49.8 & 55.1 & 27.4 \\
\hline Vietnam rat HEV (JX120573) & 56.3 & 55.2 & 58.9 & 51.6 & 50.0 & 55.5 & 29.6 \\
\hline Ferret HEV (JN998606) & 56.2 & 54.7 & 60.5 & 49.5 & 50.5 & 55.9 & 26.5 \\
\hline \multicolumn{8}{|l|}{ Orthohepevirus D } \\
\hline Germany bat HEV (JQ001749) & 53.5 & 53 & 54.8 & 47.0 & 43.7 & 47.3 & 22.9 \\
\hline \multicolumn{8}{|l|}{ Piscihepevirus A } \\
\hline Cutthroat trout HEV (HQ731075) & 48.1 & 48.5 & 47.9 & 37.4 & 28.4 & 20.2 & 15.5 \\
\hline
\end{tabular}

\section{Beyond the Species Level: HEV Genotypes and Subgenotypes}

Classification below the species level is beyond the aegis of ICTV; however, guidance on further classification into genotypes have also been proposed by Smith et al. [27]. Much of these classification efforts have focused on Orthohepevirus A, which is the most diverse species and contains several genotypes pathogenic to humans. Based on pairwise amino acid sequence comparisons of available concatenated ORF1 and ORF2 sequences (excluding the ORF1 hypervariable region) of HEV variants visualized using a $p$-distance frequency distribution histogram, a $p$-distance of 0.088 appears to mark the demarcation between intra-genotypic and inter-genotypic sequence diversity [27]. A $p$-distance greater than this threshold is, therefore, used as the definition of novel genotypes and this system enables classification of Orthohepevirus A into eight genotypes. However, the significant sequence diversity within this species appears to be a continuum and the future discovery of variants that challenge fixed definitions of genotype can be anticipated. The identification of inter-genotypic HEV recombinants infecting swine [31,34] further complicates precise genotype allocations of all strains.

Individual genotypes within Orthohepevirus A are often congruent with well-defined geographical distribution and host restriction although inter-species transmission of particular HEV genotypes has been well documented in both laboratory and field settings [35]. Genotypes 1-4 are most commonly implicated in human infection with contrasting epidemiology. Genotype 1 HEV (HEV-1) only infects humans and is the most common cause of hepatitis $\mathrm{E}$ in regions with lower socioeconomic development where it is predominantly spread via contaminated potable water. Genotype 2 HEV (HEV-2) appears to be very rare, the only complete genome sequence comes from a strain identified in Mexico; 
based on short fragments, some HEV variants identified in Africa may belong to HEV-2 as well [36,37]. HEV-3 and HEV-4 circulate in swine populations (including pigs and wild boar) and are an important cause of zoonotic foodborne autochthonous human hepatitis $\mathrm{E}$ in areas with high socioeconomic development [38]. HEV-3 is enzootic in the Americas, Europe and parts of Asia while HEV-4 is enzootic in China and Korea and is emerging as the major cause of human hepatitis $\mathrm{E}$ in the region, outcompeting HEV1 in the last decade [39-41]. HEV-5 and HEV-6 are novel genotypes identified in Japanese wild boars [42,43] and cluster together with HEV-4 isolates on phylogenetic analysis (Figure 2). HEV-7 and HEV-8 were identified in camels [44,45]; their discovery and characteristics are detailed in the next section as an illustrative example of increasing recognition of Hepeviridae diversity.
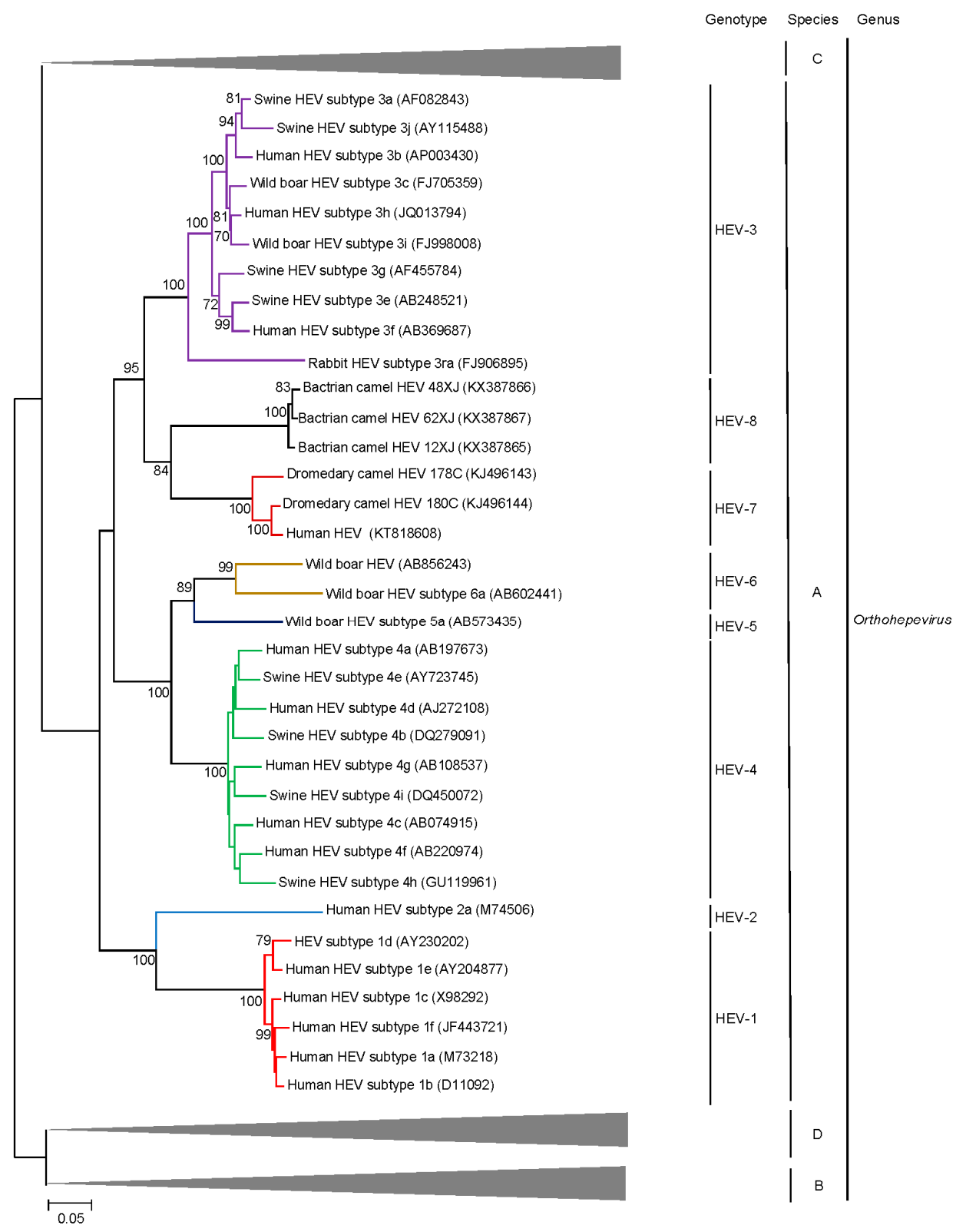

Figure 2. Phylogenetic analyses of ORF1/ORF2 proteins excluding the hypervariable region (HVR) of HEVs within the genus Orthohepevirus (Species A to D). The tree was constructed using maximum likelihood method and the optimal substitution model of JTT + G + I was used. In total, 2282 acid positions (amino acid residues 1-706 and 789-2409, numbered with reference to GenBank sequence M73218) were included in the analyses. The scale bar indicates the estimated number of substitutions per 20 amino acids. GenBank accession numbers are shown in brackets. 
Classification of the other Orthohepevirus species into genotypes has also been possible, but intra-species diversity is more limited compared to Orthohepevirus A requiring varying definitions of what constitutes a genotype. For example, the divergence among complete genome amino acid sequences of avian HEV (Orthohepevirus B) is less than 6\%, which is even lower than intra-genotypic diversity in swine HEV-3 [27]. There is sufficient diversity between rodent and ferret HEV to classify Orthohepevirus $\mathrm{C}$ into two genotypes while there is insufficient sequence information at this stage to further classify bat HEV (Orthohepevirus D) [27].

For classification of individual HEV genotypes into subtypes, the initial work of Lu et al. [24] has been expanded further by analysis of nucleotide $p$-distances of all available complete HEV genome sequences and assignment of reference sequences for each subtype [46]. HEV-1 was identified to have six subtypes divisible into two clades, HEV-3 has ten subtypes after excluding the related rabbit HEV clade, and HEV-4 has nine subtypes [46]. Subtype assignment is complex as pairwise $p$-distance variation is often a continuum within and between subtypes; this again precludes setting any fixed demarcation definition of what constitutes a subtype. Several HEV variants still await definitive subtype assignment based on the extant framework. It may be noted that viral subtype has not been correlated with clinical severity or increased inter-species transmissibility [47]. Furthermore, the study of HEV epidemiology, transmission patterns and evolution rely more on identification of clades from sequence datasets rather than precise subtype designations of individual sequences [48,49]. However, the importance of a well curated and labeled database of HEV complete genome or subgenomic sequences as an aid to epidemiological research cannot be overemphasized.

\section{Discovery of Camel HEV Genotypes}

The recent discovery of two camelid HEV genotypes by our group is an illustrative example of our rapidly expanding understanding of HEV ecology [44,45]. In 2014, we reported the discovery of camelid HEV in dromedary camels (Camelus dromedarius or one-humped camels) from Dubai and then, in 2016, in Bactrian camels (Camelus bactrianus or two-humped camels) from Xinjiang, further expanding the mammalian host diversity of HEV. These camel HEV genomes possessed $>20 \%$ nucleotide difference to all other HEVs with complete genome sequences available and, therefore, have been proposed as new genotypes of HEV (Table 1): HEV-7 for dromedary camel HEV (DcHEV) and HEV-8 for Bactrian camel HEV (BcHEV). A recent reported case of chronic HEV-7 infection in a liver transplant recipient who regularly consumed camel products [10] suggests the potential high impact to human health of novel genotypes within Orthohepevirus A.

Complete genome sequencing was performed on two DcHEV strains (DcHEV 178C and 180C) and three BcHEV strains (DcHEV 12XJ, 48XJ and 62XJ). The genome size of camel HEVs ranged from 7212 to 7223 bases, with $G+C$ content of $52.7 \%$ to $55.1 \%$ (Table 2). The camel HEV genomes contained three major ORFs, with typical genome organization and characteristics similar to other HEV genotypes of Orthohepevirus A (Figure 1). ORF1 polyprotein contained domains consistent with a methyltransferase, a peptide containing a Y-domain, a papain-like cysteine protease, a peptide with a hypervariable region (HVR), a helicase, and an RNA-dependent RNA polymerase. Conserved sequences TLYTRTWS and RRLLXXYPDG that bound the HVR of HEV-1 to HEV-6 [42,50], but not in HEVs of other Orthohepevirus species, were also present in camel HEVs. A conserved motif (T/V)SGFSS(X)F(X)P immediately preceding the HVR of HEV-3 to HEV-6, but not present in HEV-1, HEV-2 or HEVs of other Orthohepevirus species, were also present in HEV-7 and HEV-8 as VSGFSSDFAP and TSGFSSNFSP respectively. The relative excess of proline and serine observed in the HVR of all other HEVs was also observed for camel HEVs. For DcHEV strain 178C (HEV-7), ORF2 began at nt 5172, similar to HEV-4 to HEV-6 with an insertion of a single nucleotide (U) at nt 5146, and ended at nt 7154, encoding a capsid protein of 660 aa (Table 2; Figure 3). As for DcHEV strain 180C (HEV-7) and the three BcHEV strains 12XJ, 48XJ and 62XJ (HEV-8), because of the lack of U insertion as in HEV-1, HEV-2 and HEV-3, ORF2 began at nt 5171 for DcHEV strain 180C and nt 5176 for the three BcHEV strains, also encoding a capsid protein of 660 aa. For DcHEV strain 178C (HEV-7), similar to HEV-4 
to HEV-6, ORF3 began at nt 5161 and ended at nt 5502, encoding a small phosphoprotein of 113 aa with a multifunctional C-terminal region (Table 2; Figure 3). As for DcHEV strain 180C (HEV-7) and the three BcHEV strains (HEV-8), due to the lack of the U insertion as in HEV1, HEV2 and HEV3, ORF3 begain at nt 5160 for DcHEV strain 180C and nt 5165 for the three BcHEV strains (HEV-8) (Table 2; Figure 3). The conserved cis-reactive element (UGAAUAACAUGU) located upstream of ORF2 and ORF3 in the camel HEV strains might serve as promoter for the synthesis of the subgenomic mRNA for these two ORFs (Figure 3). Most interestingly, the presence of a U insertion downstream to AUG2 in DcHEV strain 178C resembled those of HEV-4 to HEV-6, leading to three possible start codons (AUG1, AUG2 or AUG4) for its ORF2 but one possible start codon for its ORF3 (AUG3), whereas the lack of this U insertion downstream to AUG2 in DcHEV strain 180C resembled those of HEV1, HEV2 and HEV3 and the three BcHEV strains (HEV-8), leading to only one possible start codon for its ORF2 (AUG4) but three possible start codons for its ORF3 (AUG1, AUG2 or AUG3) (Figure 3). The presence/absence of such a $U$ insertion in different strains of the same HEV genotype has never been observed in other HEV genotypes and is so far unique to DcHEV (HEV-7).

Table 2. Comparison of genomic organization of HEV genotypes and isolates *.

\begin{tabular}{|c|c|c|c|c|c|c|c|}
\hline $\begin{array}{l}\text { HEV Genotypes/Strains } \\
\text { (GenBank Accession No.) }\end{array}$ & $\begin{array}{l}\text { Genome } \\
\text { Length, nt }\end{array}$ & $\underset{\%}{\text { GC Content, }}$ & $\begin{array}{l}5^{\prime} \text { UTR, } \\
\text { nt }\end{array}$ & $\begin{array}{l}\text { ORF1, } \\
\text { aa }\end{array}$ & $\begin{array}{l}\text { ORF2, } \\
\text { aa }\end{array}$ & $\begin{array}{l}\text { ORF3, } \\
\text { aa }\end{array}$ & $3^{\prime}$ UTR, nt \\
\hline \multicolumn{8}{|l|}{ Orthohepevirus A } \\
\hline \multicolumn{8}{|l|}{ HEV-1 } \\
\hline Human HEV1a (M73218) & 7194 & 58.1 & 27 & 1693 & 660 & 114 & 65 \\
\hline Human HEV1b (D11092) & 7194 & 57.7 & 27 & 1693 & 660 & 123 & 66 \\
\hline Human HEV1c (X98292) & 7193 & 57.6 & 26 & 1693 & 660 & 123 & 65 \\
\hline Human HEV1d (AY230202) & 7192 & 57.4 & 25 & 1693 & 660 & 123 & 65 \\
\hline Human HEV1e (AY204877) $\S$ & $\geq 7153$ & 57.4 & NA & $\geq 1688$ & 660 & 123 & 65 \\
\hline Human HEV1f (JF443721) & 7194 & 57.7 & 27 & 1693 & 660 & 114 & 65 \\
\hline \multicolumn{8}{|l|}{ HEV-2 } \\
\hline Human HEV2a (M74506) ‡ & $\geq 7170$ & 56.5 & NA & 1691 & 659 & 114 & 74 \\
\hline \multicolumn{8}{|l|}{ HEV-3 } \\
\hline Human HEV3a (AB089824) & 7244 & 55.3 & 25 & 1709 & 660 & 113 & 72 \\
\hline Swine HEV3a (AF082843) & 7207 & 55.6 & 9 & 1708 & 660 & 122 & 54 \\
\hline Human HEV3b (AP003430) & 7230 & 55.3 & 26 & 1703 & 660 & 122 & 72 \\
\hline Wild boar HEV3c (FJ705359) & 7222 & 55.5 & 25 & 1703 & 660 & 122 & 68 \\
\hline Swine HEV3e (AB248521) & 7225 & 54.7 & 25 & 1704 & 660 & 122 & 68 \\
\hline Human HEV3f (AB369687) & 7214 & 55.5 & 5 & 1704 & 660 & 122 & 77 \\
\hline Swine HEV3g (AF455784) & 7215 & 55.9 & 28 & 1697 & 660 & 122 & 76 \\
\hline Human HEV3h (JQ013794) § & $\geq 7163$ & 56.0 & NA & $\geq 1691$ & 660 & 113 & 68 \\
\hline Wild boar HEV3i (FJ998008) & $\geq 7197$ & 55.6 & NA & 1703 & 660 & 122 & 68 \\
\hline Swine HEV3j (AY115488) & 7242 & 55.4 & 26 & 1708 & 660 & 122 & 72 \\
\hline Rabbit HEV3ra (FJ906895) $\ddagger$ & 7283 & 55.5 & 26 & 1722 & 660 & 122 & 71 \\
\hline \multicolumn{8}{|l|}{ HEV-4 } \\
\hline Human HEV4a (AB197673) & 7237 & 54.2 & 26 & 1706 & 674 & 114 & 69 \\
\hline Swine HEV4b (DQ279091) & 7234 & 54.7 & 26 & 1705 & 674 & 114 & 69 \\
\hline Human HEV4c (AB074915) & 7224 & 54.9 & 9 & 1707 & 674 & 114 & 70 \\
\hline Human HEV4d (AJ272108) & 7232 & 54.4 & 25 & 1707 & 658 & 112 & 68 \\
\hline Swine HEV4e (AY723745) & 7240 & 54.5 & 25 & 1707 & 674 & 114 & 70 \\
\hline Human HEV4f (AB220974) & 7243 & 54.3 & 25 & 1707 & 674 & 114 & 73 \\
\hline Human HEV4g (AB108537) & 7193 & 55.0 & 9 & 1706 & 674 & 114 & 42 \\
\hline Swine HEV4h (GU119961) & 7240 & 55.1 & 26 & 1707 & 674 & 114 & 69 \\
\hline Swine HEV4i (DQ450072) & 7235 & 55.2 & 26 & 1707 & 660 & 122 & 68 \\
\hline \multicolumn{8}{|l|}{ HEV-5 } \\
\hline Wild boar HEV5a (AB573435) & 7250 & 55.5 & 25 & 1708 & 674 & 112 & 77 \\
\hline \multicolumn{8}{|l|}{ HEV-6 } \\
\hline Wild boar HEV6 (AB856243) & 7247 & 55.6 & 25 & 1709 & 660 & 112 & 71 \\
\hline Wild boar HEV 6a (AB602441) & 7246 & 57.0 & 25 & 1709 & 660 & 112 & 70 \\
\hline \multicolumn{8}{|l|}{ HEV-7 } \\
\hline Human HEV7 (KT818608) § & 7220 & 52.4 & 40 & 1698 & 660 & 113 & 66 \\
\hline DcHEV-178C $(\mathrm{KJ} 496143)^{\dagger}$ & 7220 & 55.1 & 39 & 1698 & 660 & 113 & 66 \\
\hline DcHEV-180C (KJ496144) $\ddagger$ & 7219 & 54.4 & 39 & 1698 & 660 & 113 & 66 \\
\hline \multicolumn{8}{|l|}{ HEV-8 } \\
\hline BcHEV-12XJ (KX387865) & 7223 & 52.7 & 26 & 1704 & 660 & 113 & 65 \\
\hline BcHEV-48XJ (KX387866) & 7223 & 53.0 & 26 & 1704 & 660 & 113 & 65 \\
\hline BcHEV-62XJ (KX387867) & 7212 & 53.1 & 15 & 1704 & 660 & 113 & 72 \\
\hline
\end{tabular}


Table 2. Cont.

\begin{tabular}{|c|c|c|c|c|c|c|c|}
\hline $\begin{array}{l}\text { HEV Genotypes/Strains } \\
\text { (GenBank Accession No.) }\end{array}$ & $\begin{array}{l}\text { Genome } \\
\text { Length, nt }\end{array}$ & $\begin{array}{c}\text { GC Content, } \\
\%\end{array}$ & $\begin{array}{l}5^{\prime} \text { UTR, } \\
\text { nt }\end{array}$ & $\begin{array}{l}\text { ORF1, } \\
\text { aa }\end{array}$ & $\begin{array}{l}\text { ORF2, } \\
\text { aa }\end{array}$ & $\begin{array}{l}\text { ORF3, } \\
\text { aa }\end{array}$ & $3^{\prime}$ UTR, nt \\
\hline \multicolumn{8}{|l|}{ Orthohepevirus B } \\
\hline Avian HEV genotype 1 (AM943647) $\S$ & $\geq 6627$ & 55.1 & NA & $\geq 1531$ & 606 & 87 & 123 \\
\hline Avian HEV genotype 2 (AY535004) & 6654 & 55.5 & 24 & 1531 & 606 & 87 & 127 \\
\hline \multirow{2}{*}{$\begin{array}{l}\text { Avian HEV genotype } 3 \text { (AM943646) } \\
\text { Avian HEV novel unclassified } \\
\text { genotype (JN997392) }\end{array}$} & $\geq 6631$ & 55.6 & NA & 1532 & 606 & 87 & 126 \\
\hline & $\geq 6543$ & 55.7 & NA & $\geq 1515$ & 606 & 87 & NA \\
\hline \multicolumn{8}{|l|}{ Orthohepevirus C } \\
\hline Germany rat HEV (GU345042) & 6948 & 57.8 & 10 & 1636 & 644 & 102 & 65 \\
\hline Vietnam rat HEV (JX120573) & 6927 & 56.6 & 10 & 1629 & 644 & 102 & 65 \\
\hline Ferret HEV (JN998606) & 6841 & 53.8 & 12 & 1596 & 654 & 108 & 65 \\
\hline \multicolumn{8}{|l|}{ Orthohepevirus D } \\
\hline Bat HEV (JQ001749) & 6767 & 51.8 & 33 & 1580 & 637 & 137 & 77 \\
\hline \multicolumn{8}{|l|}{ Piscihepevirus A } \\
\hline Cutthroat trout HEV (HQ731075) & 7269 & 49.7 & 100 & 1707 & 634 & 225 & 76 \\
\hline
\end{tabular}

${ }^{*} \mathrm{HEV}$, hepatitis E virus; UTR, untranslated region; ORF, open reading frame; BcHEV, HEV from Bactrian camel; DcHEV, HEV from dromedary camel; NA, not available because of incomplete genome; ${ }^{\dagger}$ Assuming the third AUG of ORF2 is the start codon; ${ }^{\ddagger}$ Assuming the third AUG of ORF3 is the start codon; ${ }^{\S}$ Near-complete genome.

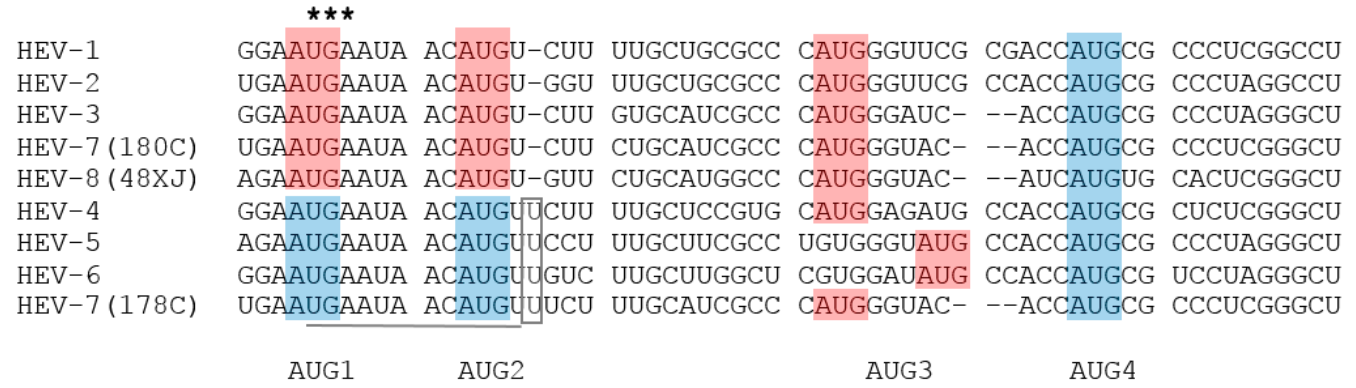

Figure 3. Alignment of nucleotide sequences showing potential start codons for ORF2 and ORF3 in HEV-1 to HEV-8. Potential start codons of ORF3 are shaded by red boxes, and those of ORF2 by blue boxes. The inserted $U$ residues are indicated by open box. The stop codon of ORF1 is marked with asterisks. The conserved cis-reactive element with the sequence UGAAUAACAUGU is underlined, which might serve as promoter for the synthesis of the subgenomic mRNA for the ORF2 and ORF3.

Phylogenetic trees constructed using concatenated ORF1/ORF2 excluding the HVR (Figure 2), ORF1 (Figure 4), ORF2 (Figure 5), ORF3 (Figure 6) and showed that the three Bactrian camel HEV strains (HEV-8) were clustered with the two dromedary camel HEV strains (HEV-7) and the HEV-7 strain from the liver-transplant recipient with chronic hepatitis [10], and they were clustered with different HEVs in different phylogenetic trees. For ORF1 and concatenated ORF1/ORF2 excluding the HVR, HEV-7 and HEV-8 were clustered with HEV-3. However, they were clustered with HEV-1 and HEV-2 for ORF2 and clustered with HEV-2 for ORF3, but with low bootstrap support. Although different regions of the camel HEV genomes may be more similar to different genotypes of HEV, recombinational analysis performed using bootscan analysis revealed no obvious and definite site of recombination. Amino acid distances based on the concatenated ORF1/ORF2 excluding the HVR region of HEV-7 and HEV-8, and those of camel HEVs and the existing genotypes were $\geq 0.1$, which was greater than the threshold (i.e., $p$-distance $=0.088$ ) to demarcate inter-genotype distance [27] (Table 3), supporting that the camel HEVs should constitute two different HEV genotypes, for which HEV-7 and HEV-8 were proposed for DcHEV and BcHEV, respectively. 

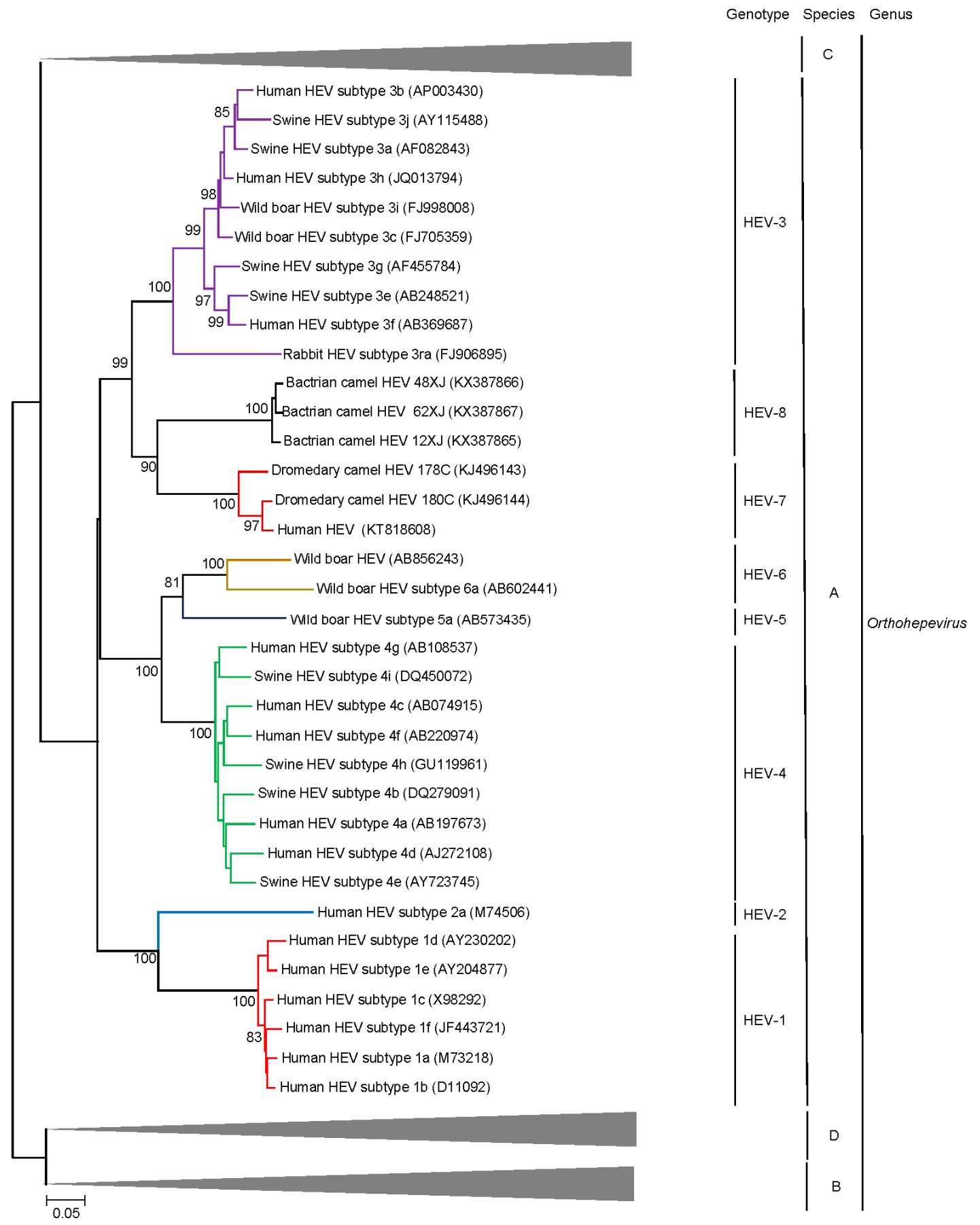

Figure 4. Phylogenetic analyses of ORF1of HEVs within the genus Orthohepevirus (Species A to D). The tree was constructed using maximum likelihood method and the optimal substitution model of $\mathrm{JTT}+\mathrm{G}+\mathrm{I}+\mathrm{F}$ was used. Amino acid residues 1-1743 in ORF1, numbered with reference to GenBank sequence M73218, were included in the analyses. The scale bar indicates the estimated number of substitutions per 20 amino acids. GenBank accession numbers are shown in brackets. 


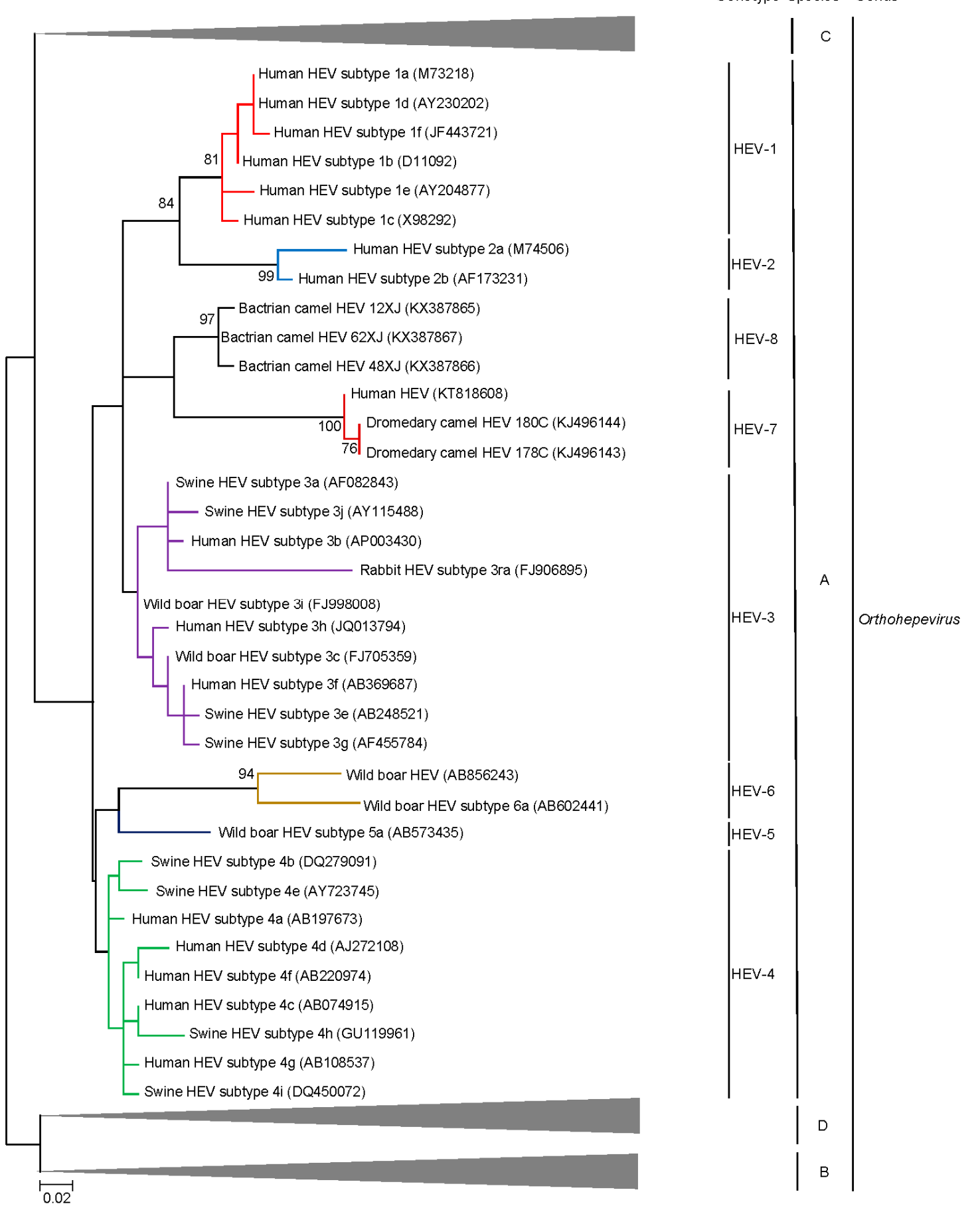

Figure 5. Phylogenetic analyses of ORF2 of HEVs within the genus Orthohepevirus (Species A to D). The tree was constructed using maximum likelihood method and the optimal substitution model of JTT $+\mathrm{G}+\mathrm{I}$ was used. Amino acid residues 1-660 in ORF2, numbered with reference to GenBank sequence M73218, were included in the analyses. The scale bar indicates the estimated number of substitutions per 50 amino acids. GenBank accession numbers are shown in brackets. 

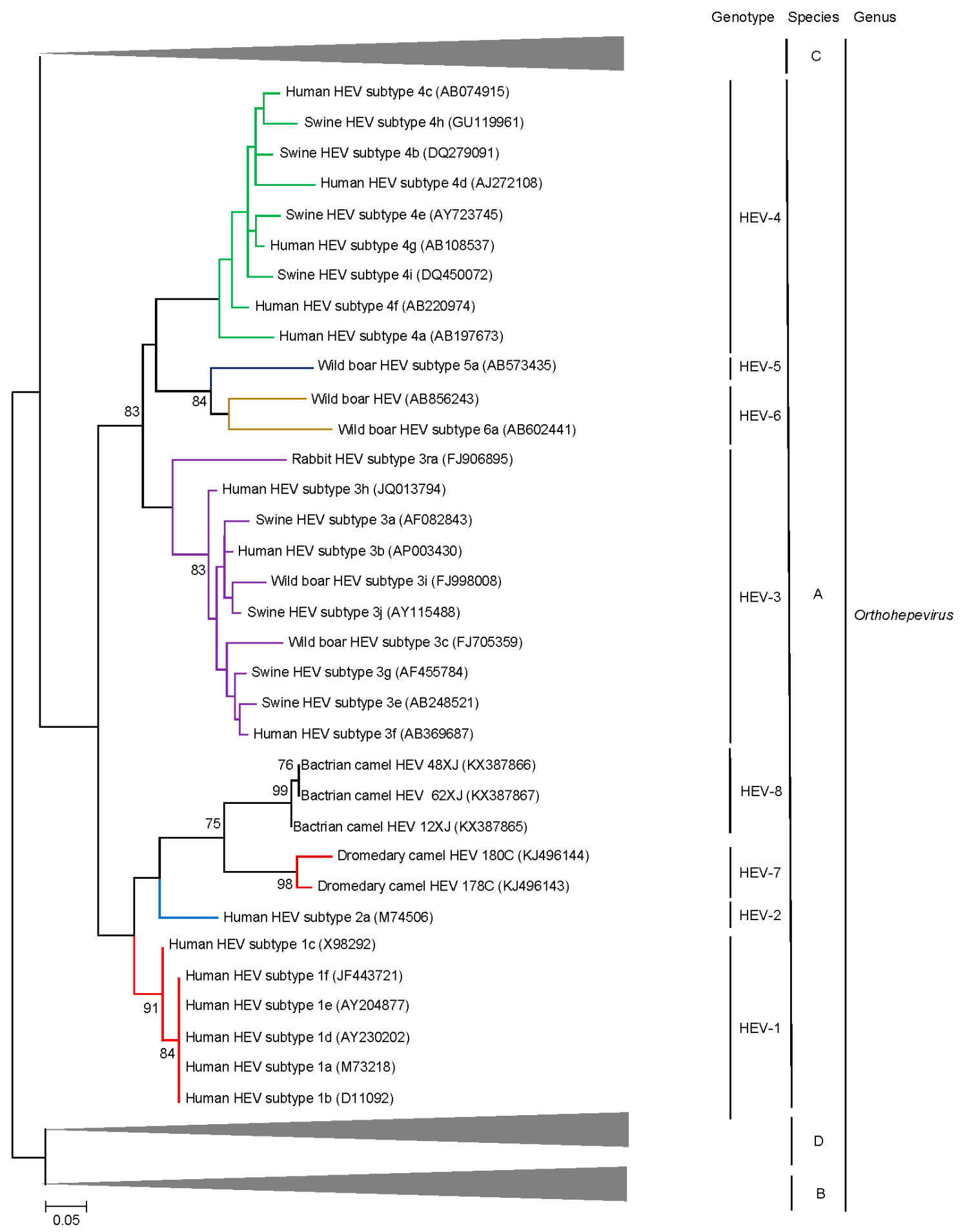

Figure 6. Phylogenetic analyses of ORF3 of HEVs within the genus Orthohepevirus (Species A to D). The tree was constructed using maximum likelihood method and the optimal substitution model of JTT + G was used. Amino acid residues 10-123 in ORF3, numbered with reference to GenBank sequence M73218, were included in the analyses. The scale bar indicates the estimated number of substitutions per 20 amino acids. GenBank accession numbers are shown in brackets. 
Table 3. $p$-Distance of the three BcHEV strains and other genotypes of HEV based on amino acid of ORF1/ORF2 excluding HVR region *.

\begin{tabular}{|c|c|c|c|}
\hline \multirow{2}{*}{ HEV Genotypes/Strains (GenBank Accession No.) } & \multicolumn{3}{|c|}{$p$-Distance with Strain } \\
\hline & BcHEV-12XJ & BcHEV-48XJ & BcHEV-62XJ \\
\hline \multicolumn{4}{|l|}{ HEV-8 } \\
\hline BcHEV-12XJ & - & 0.011 & 0.009 \\
\hline BcHEV-48XJ & 0.011 & - & 0.006 \\
\hline BcHEV-62XJ & 0.009 & 0.006 & - \\
\hline \multicolumn{4}{|l|}{ HEV-1 } \\
\hline Human HEV subtype 1a (M73218) & 0.143 & 0.143 & 0.141 \\
\hline Human HEV subtype 1b (D11092) & 0.141 & 0.142 & 0.140 \\
\hline Human HEV subtype 1c (X98292) & 0.140 & 0.140 & 0.139 \\
\hline Human HEV subtype 1d (AY230202) & 0.139 & 0.138 & 0.136 \\
\hline Human HEV subtype 1f (JF443721) & 0.143 & 0.143 & 0.141 \\
\hline \multicolumn{4}{|l|}{ HEV-2 } \\
\hline Human HEV subtype 2a (M74506) ${ }^{\dagger}$ & 0.156 & 0.156 & 0.155 \\
\hline \multicolumn{4}{|l|}{ HEV-3 } \\
\hline Swine HEV subtype 3a (AF082843) & 0.106 & 0.105 & 0.106 \\
\hline Human HEV subtype 3b (AP003430) & 0.103 & 0.103 & 0.104 \\
\hline Wild boar HEV subtype 3c (FJ705359) & 0.100 & 0.100 & 0.101 \\
\hline Swine HEV subtype 3e (AB248521) & 0.104 & 0.105 & 0.105 \\
\hline Human HEV subtype 3f (AB369687) & 0.105 & 0.105 & 0.105 \\
\hline Swine HEV subtype $3 g$ (AF455784) & 0.103 & 0.105 & 0.105 \\
\hline Wild boar HEV subtype 3i (FJ998008) ${ }^{\dagger}$ & 0.101 & 0.101 & 0.102 \\
\hline Swine HEV subtype 3j (AY115488) & 0.109 & 0.109 & 0.110 \\
\hline Rabbit HEV subtype 3ra (FJ906895) & 0.132 & 0.133 & 0.132 \\
\hline \multicolumn{4}{|l|}{ HEV-4 } \\
\hline Human HEV subtype 4a (AB197673) & 0.122 & 0.121 & 0.120 \\
\hline Swine HEV subtype 4b (DQ279091) & 0.124 & 0.121 & 0.120 \\
\hline Human HEV subtype 4c (AB074915) & 0.123 & 0.121 & 0.120 \\
\hline Human HEV subtype 4d (AJ272108) & 0.127 & 0.125 & 0.124 \\
\hline Swine HEV subtype 4e (AY723745) & 0.120 & 0.119 & 0.119 \\
\hline Human HEV subtype 4f (AB220974) & 0.127 & 0.125 & 0.124 \\
\hline Human HEV subtype 4g (AB108537) & 0.121 & 0.119 & 0.118 \\
\hline Swine HEV subtype 4h (GU119961) & 0.134 & 0.132 & 0.131 \\
\hline Swine HEV subtype 4i (DQ450072) & 0.132 & 0.130 & 0.129 \\
\hline \multicolumn{4}{|l|}{ HEV-5 } \\
\hline Wild boar HEV subtype 5a (AB573435) & 0.139 & 0.140 & 0.140 \\
\hline \multicolumn{4}{|l|}{ HEV-6 } \\
\hline Wild boar HEV 6 (AB856243) & 0.139 & 0.140 & 0.139 \\
\hline Wild boar HEV subtype 6a (AB602441) & 0.147 & 0.149 & 0.148 \\
\hline \multicolumn{4}{|l|}{ HEV-7 } \\
\hline DcHEV 7 (KJ496144) & 0.108 & 0.107 & 0.106 \\
\hline Human HEV 7 (KT818608) ${ }^{\dagger}$ & 0.108 & 0.107 & 0.105 \\
\hline DcHEV subtype 7a (KJ496143) & 0.110 & 0.109 & 0.108 \\
\hline
\end{tabular}

\section{Delving into the Sequence: Recent Insights into HEV Molecular Epidemiology and Evolution}

Rapidly accumulating sequence information over the last two decades has enabled new insights into the evolution of HEV and its adaptation to new hosts. Such studies have largely focused on HEV-1, HEV-3 and HEV-4 in view of the relative importance to human health of these HEV genotypes and abundance of publicly available sequence information. Questions addressed include the ancient 
origins of HEV, reasons for current genotypic distribution, host restriction, zoonotic transmission, local epidemiological trends, and potential future evolutionary trends of this family.

A recent systematic search for homologs of various HEV proteins in other viral families showed that the HEV1 RdRp protein sequence shares greater identity with insect viruses (Alphatetraviridae) and plant viruses (Benyviridae, Betaflexiviridae and Virgaviridae) compared to mammalian viruses [51]. However, phylogenetic analysis of the HEV ORF2 protein shows that it clusters together with members of the family Astroviridae and is quite distant from the aforementioned RdRp-homologous viral families; similarities in capsid crystal structure between astroviruses and HEV have also been noted lending credence to the theory of common ancestry $[52,53]$. Although convergent molecular evolution of genes encoding conserved enzymatic functions may theoretically be observed among unrelated viral families, this intriguing contrast in structural and non-structural protein phylogeny indicates a recombination event between the ORF1 sequence of insect/plant viruses and the ORF2 sequence of Astroviridae ancestors to produce a hybrid Hepeviridae ancestor.

Divergence analysis of HEV1-4 suggests that the split into zoonotic and anthropotropic genotypes occurred approximately 536 to 1344 years ago although significant underestimation due to the limitations of evolutionary models is possible [54]. HEV-1 appears to be more recent than the zoonotic genotypes with the estimated time to most recent common ancestor (TMRCA) of most modern lineages of HEV-1 being 87-199 years ago [54]. Population dynamics of HEV-1, HEV-3 and HEV-4 over the last century have also been described linking fluctuations in effective population size to global trade, wars, fluctuations in pork consumption, increased recognition of hepatitis $\mathrm{E}$ as a zoonosis and control measures in swine [54,55].

Comparison of non-synonymous ( $\mathrm{dN}$ ) and synonymous (dS) substitutions in each codon position of HEV genotypes 1, 3 and 4 reveals that most of the HEV genome is under purifying selection $(\mathrm{dN}<\mathrm{dS})$ irrespective of genotype. Exceptions are the hypervariable region of ORF1 and the ORF2/ORF3 overlap region, which appear to be under positive selection, a trend that is especially prominent in the zoonotic genotypes HEV-3 and HEV-4 [54,56]. Evolutionary rates differ between genotypes within Orthohepevirus A; HEV-3 and HEV-4 appear to have higher substitution rates over time and fewer conserved sites than HEV-1 across the entire genome [56]. Furthermore, codon usage bias of HEV-3 and HEV-4 ORFs tends to be lower than HEV-1 [57]. It is postulated that these findings may reflect the need of zoonotic genotypes to adapt to multiple hosts and therefore different cell types with distinct microenvironments and codon usage preferences. However, such host-specific adaptations at the molecular level could not be demonstrated in experimentally infected pigs inoculated with a HEV-3f isolate derived from a human [58]. Studies have attempted to link observed HEV sequence variations to viral host-specificity markers and inter-species transmissibility, but functional confirmation of such in silico analyses is still pending $[59,60]$.

Evolutionary dynamics of HEV on a short-term local scale have been studied to explain the pattern of locally predominant subtypes. Transregional flow of HEV-4 across provinces in China has been demonstrated by phylogenetic and coalescent-based inference [61]. Similarly, Nakano et al. were able to demonstrate the indigenization of European HEV-3e variants in Mie prefecture of Japan in both humans and wild boar [62,63] probably through importation of large-race pigs from Europe approximately fifty years ago. Similar analyses have been conducted for HEV strains sequenced in Europe [64,65].

Intra-host viral evolution has also been recognized in immunocompromised individuals with chronic hepatitis E infection. Analogous to other chronic viral infections [66-68], HEV in chronically infected patients exists in the form of a cloud of closely-related variants which may potentially exhibit quasispecies behavior. These variants likely arise due to fluctuating immunological pressures from the host; composition of viral population tends to stabilize over time without treatment [69]. Such viral heterogeneity may have direct clinical consequences; Kamar et al. reported neurological symptoms in a renal transplant recipient with chronic HEV infection and identified distinct potentially neurotropic quasispecies in the patient's cerebrospinal fluid [70], while Lhomme and colleagues have reported that 
increased quasispecies heterogeneity in the polyproline and macro regions of ORF1 may potentially be linked to chronic infections in immunocompromised hosts [71,72]. Viral heterogeneity is also of importance in patients receiving ribavirin treatment. While ribavirin may have multiple mechanisms of action including direct antiviral effects, depletion of intracellular guanosine triphosphate pools and immunomodulatory mechanisms, the prevailing hypothesis is that it induces viral mutagenesis at a rate beyond the error threshold pushing the population into extinction [73,74]. There is clear evidence for increased viral heterogeneity in ribavirin treated patients assessed using next generation sequencing. While ribavirin is the only effective antiviral available for chronic HEV infection, some patients are observed to be treatment refractory. In such patients, viral variants with mutations in the HEV RdRp region are selected out (e.g., G1634R, K1383N, D1384G, and K1398R) during treatment; the significance of these mutations in determining the ribavirin resistant phenotype is uncertain due to the difficulty in conducting in vitro studies and lack of widely accessible animal models $[69,75,76]$.

While considerable advances have been made in the last decade towards an understanding of the molecular evolution and epidemiology of HEV variants of clinical importance, further high-quality complete genome sequences of other genotypes within Orthohepevirus A (including wild boar and camelid HEV) will be required so that these genotypes may be included in analyses. This is of vital importance due to the recent description of chronic camelid HEV infection in an immunocompromised patient [10] and possible transmission of wild boar HEV genotypes to humans [35], which indicates that zoonotic HEV from non-swine sources may be an emerging underestimated cause of hepatitis in humans. Further intensive studies to elucidate inter-species transmission patterns of these novel genotypes are required.

\section{Conclusions: Future Directions}

Our understanding of the diversity of the family Hepeviridae is constantly evolving. With accumulating sequence information and discovery of novel genotypes, it is likely that taxonomic classifications will require constant revisions to keep pace with advances. Future directions may include targeted discovery programs looking for novel Orthohepevirus A genotypes in artiodactyls living in close proximity with humans. Recent advances in metagenomic approaches and next-generation sequencing could greatly streamline this process and may potentially identify novel sources and routes of transmission. From the clinical perspective, due to the high degree of capsid structure amino acid identity among different genotypes within Orthohepevirus A, increasing evidence for zoonotic transmission from non-swine sources will be expected to accumulate. In particular, the importance of camelid hepatitis $\mathrm{E}$ genotypes in causing human hepatitis in enzootic areas urgently requires further study. Furthermore, constant vigilance for novel recombinants will be required. The ever-increasing cache of genomic data and sophisticated models will be useful to address questions related to HEV evolution and epidemiology; a preponderance of the extant data originates from Europe and East Asia, extending their approaches to other parts of the world will enable us to capture a global perspective and identify previously missed links. Finally, a better understanding of intra-host evolution of HEV during human infection may enable us to predict clinical outcomes and treatment response in patients at risk of chronic and fulminant HEV infection.

Author Contributions: Siddharth Sridhar wrote the manuscript; Jade L. L. Teng prepared the figures and wrote the section on camelid HEV; Tsz-Ho Chiu prepared the tables; and Susanna K. P. Lau and Patrick C. Y. Woo conceived the format of the manuscript and edited it.

Conflicts of Interest: The authors declare no conflicts of interest.

\section{References}

1. WHO. Hepatitis E Fact Sheet. Available online: http://www.who.int/mediacentre/factsheets/fs280/en/ (accessed on 15 February 2017). 
2. Ren, X.; Wu, P.; Wang, L.; Geng, M.; Zeng, L.; Zhang, J.; Xia, N.; Lai, S.; Dalton, H.R.; Cowling, B.J.; et al. Changing epidemiology of hepatitis A and hepatitis E viruses in China, 1990-2014. Emerg. Infect. Dis. 2017, 23, 276-279. [CrossRef] [PubMed]

3. Jin, H.; Zhao, Y.; Zhang, X.; Wang, B.; Liu, P. Case-fatality risk of pregnant women with acute viral hepatitis type E: A systematic review and meta-analysis. Epidemiol. Infect. 2016, 144, 2098-2106. [CrossRef] [PubMed]

4. Kamar, N.; Selves, J.; Mansuy, J.M.; Ouezzani, L.; Peron, J.M.; Guitard, J.; Cointault, O.; Esposito, L.; Abravanel, F.; Danjoux, M.; et al. Hepatitis E virus and chronic hepatitis in organ-transplant recipients. N. Engl. J. Med. 2008, 358, 811-817. [CrossRef] [PubMed]

5. Giordani, M.T.; Fabris, P.; Brunetti, E.; Goblirsch, S.; Romano, L. Hepatitis E and lymphocytic leukemia in Man, Italy. Emerg. Infect. Dis. 2013, 19, 2054-2056. [CrossRef] [PubMed]

6. Neukam, K.; Barreiro, P.; Macias, J.; Avellon, A.; Cifuentes, C.; Martin-Carbonero, L.; Echevarria, J.M.; Vargas, J.; Soriano, V.; Pineda, J.A. Chronic hepatitis E in HIV patients: Rapid progression to cirrhosis and response to oral ribavirin. Clin. Infect. Dis. 2013, 57, 465-468. [CrossRef] [PubMed]

7. WHO. The Global Prevalence of Hepatitis E Viral Prevalence and Susceptibility: A Systematic Review. Available online: http://apps.who.int/iris/bitstream/10665/70513/1/WHO_IVB_10.14_eng.pdf?ua=1 (accessed on 15 February 2017).

8. Sridhar, S.; Lau, S.K.; Woo, P.C. Hepatitis E: A disease of reemerging importance. J. Formos. Med. Assoc. 2015, 114, 681-690. [CrossRef] [PubMed]

9. Tei, S.; Kitajima, N.; Takahashi, K.; Mishiro, S. Zoonotic transmission of hepatitis E virus from deer to human beings. Lancet 2003, 362, 371-373. [CrossRef]

10. Lee, G.H.; Tan, B.H.; Teo, E.C.; Lim, S.G.; Dan, Y.Y.; Wee, A.; Aw, P.P.; Zhu, Y.; Hibberd, M.L.; Tan, C.K.; et al. Chronic infection with camelid hepatitis $\mathrm{E}$ virus in a liver transplant recipient who regularly consumes camel meat and milk. Gastroenterology 2016, 150, 355-357. [CrossRef] [PubMed]

11. Kim, Y.M.; Jeong, S.H.; Kim, J.Y.; Song, J.C.; Lee, J.H.; Kim, J.W.; Yun, H.; Kim, J.S. The first case of genotype 4 hepatitis E related to wild boar in South Korea. J. Clin. Virol. 2011, 50, 253-256. [CrossRef] [PubMed]

12. Li, T.C.; Chijiwa, K.; Sera, N.; Ishibashi, T.; Etoh, Y.; Shinohara, Y.; Kurata, Y.; Ishida, M.; Sakamoto, S.; Takeda, N.; et al. Hepatitis E virus transmission from wild boar meat. Emerg. Infect. Dis. 2005, 11, 1958-1960. [CrossRef] [PubMed]

13. Izopet, J.; Dubois, M.; Bertagnoli, S.; Lhomme, S.; Marchandeau, S.; Boucher, S.; Kamar, N.; Abravanel, F.; Guerin, J.L. Hepatitis E virus strains in rabbits and evidence of a closely related strain in humans, France. Emerg. Infect. Dis. 2012, 18, 1274-1281. [CrossRef] [PubMed]

14. Debing, Y.; Moradpour, D.; Neyts, J.; Gouttenoire, J. Update on hepatitis E virology: Implications for clinical practice. J. Hepatol. 2016, 65, 200-212. [CrossRef] [PubMed]

15. Graff, J.; Torian, U.; Nguyen, H.; Emerson, S.U. A bicistronic subgenomic mRNA encodes both the ORF2 and ORF3 proteins of hepatitis E virus. J. Virol. 2006, 80, 5919-5926. [CrossRef] [PubMed]

16. Koonin, E.V.; Gorbalenya, A.E.; Purdy, M.A.; Rozanov, M.N.; Reyes, G.R.; Bradley, D.W. Computer-assisted assignment of functional domains in the nonstructural polyprotein of hepatitis E virus: Delineation of an additional group of positive-strand RNA plant and animal viruses. Proc. Natl. Acad. Sci. USA 1992, 89, 8259-8263. [CrossRef] [PubMed]

17. Panda, S.K.; Varma, S.P. Hepatitis E: Molecular virology and pathogenesis. J. Clin. Exp. Hepatol. 2013, 3, 114-124. [CrossRef] [PubMed]

18. Kannan, H.; Fan, S.; Patel, D.; Bossis, I.; Zhang, Y.J. The hepatitis E virus open reading frame 3 product interacts with microtubules and interferes with their dynamics. J. Virol. 2009, 83, 6375-6382. [CrossRef] [PubMed]

19. Nagashima, S.; Takahashi, M.; Jirintai, S.; Tanggis; Kobayashi, T.; Nishizawa, T.; Okamoto, H. The membrane on the surface of hepatitis E virus particles is derived from the intracellular membrane and contains trans-golgi network protein 2. Arch. Virol. 2014, 159, 979-991. [CrossRef] [PubMed]

20. Yang, T.; Kataoka, M.; Ami, Y.; Suzaki, Y.; Kishida, N.; Shirakura, M.; Imai, M.; Asanuma, H.; Takeda, N.; Wakita, T.; et al. Characterization of self-assembled virus-like particles of ferret hepatitis $\mathrm{E}$ virus generated by recombinant Baculoviruses. J. Gen. Virol. 2013, 94, 2647-2656. [CrossRef] [PubMed]

21. Zhou, X.; Kataoka, M.; Liu, Z.; Takeda, N.; Wakita, T.; Li, T.C. Characterization of self-assembled virus-like particles of dromedary camel hepatitis E virus generated by recombinant Baculoviruses. Virus. Res. 2015, 210, 8-17. [CrossRef] [PubMed] 
22. Wang, S.; Cheng, X.; Dai, X.; Dong, C.; Xu, M.; Liang, J.; Dong, M.; Purdy, M.A.; Meng, J. Rabbit and human hepatitis E virus strains belong to a single serotype. Virus Res. 2013, 176, 101-106. [CrossRef] [PubMed]

23. Wang, S.; Dong, C.; Dai, X.; Cheng, X.; Liang, J.; Dong, M.; Purdy, M.A.; Meng, J. Hepatitis E virus isolated from rabbits is genetically heterogeneous but with very similar antigenicity to human HEV. J. Med. Virol. 2013, 85, 627-635. [CrossRef] [PubMed]

24. Lu, L.; Li, C.; Hagedorn, C.H. Phylogenetic analysis of global hepatitis E virus sequences: Genetic diversity, subtypes and zoonosis. Rev. Med. Virol. 2006, 16, 5-36. [CrossRef] [PubMed]

25. Schlauder, G.G.; Desai, S.M.; Zanetti, A.R.; Tassopoulos, N.C.; Mushahwar, I.K. Novel hepatitis E virus (HEV) isolates from europe: Evidence for additional genotypes of HEV. J. Med. Virol. 1999, 57, 243-251. [CrossRef]

26. Schlauder, G.G.; Mushahwar, I.K. Genetic heterogeneity of hepatitis E virus. J. Med. Virol. 2001, 65, $282-292$. [CrossRef] [PubMed]

27. Smith, D.B.; Simmonds, P.; International Committee on Taxonomy of Viruses Hepeviridae Study Group; Jameel, S.; Emerson, S.U.; Harrison, T.J.; Meng, X.J.; Okamoto, H.; Van der Poel, W.H.; Purdy, M.A. Consensus proposals for classification of the family Hepeviridae. J. Gen. Virol. 2014, 95, 2223-2232. [CrossRef] [PubMed]

28. Smith, D.B.; Purdy, M.A.; Simmonds, P. Genetic variability and the classification of hepatitis E virus. J. Virol. 2013, 87, 4161-4169. [CrossRef] [PubMed]

29. Worm, H.C.; van der Poel, W.H.; Brandstatter, G. Hepatitis E: An overview. Microbes Infect. 2002, 4, 657-666. [CrossRef]

30. Gouvea, V.; Hoke, C.H., Jr.; Innis, B.L. Genotyping of hepatitis E virus in clinical specimens by restriction endonuclease analysis. J. Virol. Methods 1998, 70, 71-78. [CrossRef]

31. Fan, J. Open reading frame structure analysis as a novel genotyping tool for hepatitis $\mathrm{E}$ virus and the subsequent discovery of an inter-genotype recombinant. J. Gen. Virol. 2009, 90, 1353-1358. [CrossRef] [PubMed]

32. ICTV. Virus Taxonomy: 2015 Release. Available online: https://talk.ictvonline.org/taxonomy/ (accessed on 17 February 2017).

33. Batts, W.; Yun, S.; Hedrick, R.; Winton, J. A novel member of the family Hepeviridae from cutthroat trout (Oncorhynchus clarkii). Virus. Res. 2011, 158, 116-123. [CrossRef] [PubMed]

34. Chen, X.; Zhang, Q.; He, C.; Zhang, L.; Li, J.; Zhang, W.; Cao, W.; Lv, Y.G.; Liu, Z.; Zhang, J.X.; et al. Recombination and natural selection in hepatitis E virus genotypes. J. Med. Virol. 2012, 84, 1396-1407. [CrossRef] [PubMed]

35. Meng, X.J. Expanding host range and cross-species infection of hepatitis E virus. PLoS Pathog. 2016, 12, e1005695. [CrossRef] [PubMed]

36. Fierro, N.A.; Realpe, M.; Meraz-Medina, T.; Roman, S.; Panduro, A. Hepatitis E virus: An ancient hidden enemy in Latin America. World J. Gastroenterol. 2016, 22, 2271-2283. [PubMed]

37. Huang, C.C.; Nguyen, D.; Fernandez, J.; Yun, K.Y.; Fry, K.E.; Bradley, D.W.; Tam, A.W.; Reyes, G.R. Molecular cloning and sequencing of the Mexico isolate of hepatitis E virus (HEV). Virology 1992, 191, 550-558. [CrossRef]

38. Pavio, N.; Meng, X.J.; Doceul, V. Zoonotic origin of hepatitis E. Curr. Opin. Virol. 2015, 10, 34-41. [CrossRef] [PubMed]

39. Jeong, S.H.; Park, B.J.; Kim, Y.H.; Choi, Y.S.; Ahn, H.S.; Han, S.H.; Choi, I.S. Isolation of hepatitis E virus genotype 4 from patients with acute cryptogenic hepatitis in Korea. J. Clin. Virol. 2017, 89, 10-13. [CrossRef] [PubMed]

40. Wang, L.; Geng, J. Acute hepatitis E virus infection in patients with acute liver failure in China: Not quite an uncommon cause. Hepatology 2016. [CrossRef] [PubMed]

41. Wang, L.; Liu, L.; Wei, Y.; Wang, Q.; Tian, Q.; Wang, L.; Zhuang, H. Clinical and virological profiling of sporadic hepatitis E virus infection in China. J. Infect. 2016, 73, 271-279. [CrossRef] [PubMed]

42. Takahashi, M.; Nishizawa, T.; Sato, H.; Sato, Y.; Jirintai; Nagashima, S.; Okamoto, H. Analysis of the full-length genome of a hepatitis E virus isolate obtained from a wild boar in Japan that is classifiable into a novel genotype. J. Gen. Virol. 2011, 92, 902-908. [CrossRef] [PubMed]

43. Sato, Y.; Sato, H.; Naka, K.; Furuya, S.; Tsukiji, H.; Kitagawa, K.; Sonoda, Y.; Usui, T.; Sakamoto, H.; Yoshino, S.; et al. A nationwide survey of hepatitis E virus (HEV) infection in wild boars in Japan: Identification of boar HEV strains of genotypes 3 and 4 and unrecognized genotypes. Arch. Virol. 2011, 156, 1345-1358. [CrossRef] [PubMed] 
44. Woo, P.C.; Lau, S.K.; Teng, J.L.; Cao, K.Y.; Wernery, U.; Schountz, T.; Chiu, T.H.; Tsang, A.K.; Wong, P.C.; Wong, E.Y.; et al. New hepatitis E virus genotype in Bactrian camels, Xinjiang, China, 2013. Emerg. Infect. Dis. 2016, 22, 2219-2221. [CrossRef] [PubMed]

45. Woo, P.C.; Lau, S.K.; Teng, J.L.; Tsang, A.K.; Joseph, M.; Wong, E.Y.; Tang, Y.; Sivakumar, S.; Xie, J.; Bai, R.; et al. New hepatitis E virus genotype in camels, the Middle East. Emerg. Infect. Dis. 2014, 20, 1044-1048. [CrossRef] [PubMed]

46. Smith, D.B.; Simmonds, P.; Izopet, J.; Oliveira-Filho, E.F.; Ulrich, R.G.; Johne, R.; Koenig, M.; Jameel, S.; Harrison, T.J.; Meng, X.J.; et al. Proposed reference sequences for hepatitis E virus subtypes. J. Gen. Virol. 2016, 97, 537-542. [CrossRef] [PubMed]

47. Smith, D.B.; Ijaz, S.; Tedder, R.S.; Hogema, B.; Zaaijer, H.L.; Izopet, J.; Bradley-Stewart, A.; Gunson, R.; Harvala, H.; Kokki, I.; et al. Variability and pathogenicity of hepatitis E virus genotype 3 variants. J. Gen. Virol. 2015, 96, 3255-3264. [CrossRef] [PubMed]

48. Ijaz, S.; Said, B.; Boxall, E.; Smit, E.; Morgan, D.; Tedder, R.S. Indigenous hepatitis E in England and Wales from 2003 to 2012: Evidence of an emerging novel phylotype of viruses. J. Infect. Dis. 2014, 209, 1212-1218. [CrossRef] [PubMed]

49. Oliveira-Filho, E.F.; Konig, M.; Thiel, H.J. Genetic variability of HEV isolates: Inconsistencies of current classification. Vet. Microbiol. 2013, 165, 148-154. [CrossRef] [PubMed]

50. Purdy, M.A.; Lara, J.; Khudyakov, Y.E. The hepatitis E virus polyproline region is involved in viral adaptation. PLoS ONE 2012, 7, e35974. [CrossRef] [PubMed]

51. Kelly, A.G.; Netzler, N.E.; White, P.A. Ancient recombination events and the origins of hepatitis E virus. BMC Evol. Biol. 2016, 16, 210. [CrossRef] [PubMed]

52. Dryden, K.A.; Tihova, M.; Nowotny, N.; Matsui, S.M.; Mendez, E.; Yeager, M. Immature and mature human astrovirus: Structure, conformational changes, and similarities to hepatitis E virus. J. Mol. Biol. 2012, 422, 650-658. [CrossRef] [PubMed]

53. Toh, Y.; Harper, J.; Dryden, K.A.; Yeager, M.; Arias, C.F.; Mendez, E.; Tao, Y.J. Crystal structure of the human astrovirus capsid protein. J. Virol. 2016, 90, 9008-9017. [CrossRef] [PubMed]

54. Purdy, M.A.; Khudyakov, Y.E. Evolutionary history and population dynamics of hepatitis E virus. PLoS ONE 2010, 5, e14376. [CrossRef] [PubMed]

55. Mirazo, S.; Mir, D.; Bello, G.; Ramos, N.; Musto, H.; Arbiza, J. New insights into the hepatitis E virus genotype 3 phylodynamics and evolutionary history. Infect. Genet. Evol. 2016, 43, 267-273. [CrossRef] [PubMed]

56. Brayne, A.B.; Dearlove, B.L.; Lester, J.S.; Kosakovsky Pond, S.L.; Frost, S.D. Genotype-specific evolution of hepatitis E virus. J. Virol. 2017. [CrossRef] [PubMed]

57. Bouquet, J.; Cherel, P.; Pavio, N. Genetic characterization and codon usage bias of full-length hepatitis E virus sequences shed new lights on genotypic distribution, host restriction and genome evolution. Infect. Genet. Evol. 2012, 12, 1842-1853. [CrossRef] [PubMed]

58. Bouquet, J.; Cheval, J.; Rogee, S.; Pavio, N.; Eloit, M. Identical consensus sequence and conserved genomic polymorphism of hepatitis E virus during controlled interspecies transmission. J. Virol. 2012, 86, 6238-6245. [CrossRef] [PubMed]

59. Fu, H.; Wang, L.; Zhu, Y.; Geng, J.; Li, L.; Wang, X.; Bu, Q.; Zhuang, H. Analysing complete genome sequence of swine hepatitis E virus (HEV), strain chn-xj-sw13 isolated from Xinjiang, China: Putative host range, and disease severity determinants in HEV. Infect. Genet. Evol. 2011, 11, 618-623. [CrossRef] [PubMed]

60. Geng, J.; Fu, H.; Wang, L.; Bu, Q.; Liu, P.; Wang, M.; Sui, Y.; Wang, X.; Zhu, Y.; Zhuang, H. Phylogenetic analysis of the full genome of rabbit hepatitis E virus (RBHEV) and molecular biologic study on the possibility of cross species transmission of RBHEV. Infect. Genet. Evol. 2011, 11, 2020-2025. [CrossRef] [PubMed]

61. Yang, D.; Jiang, M.; Jin, M.; Qiu, Z.G.; Shen, Z.Q.; Cui, W.H.; Wang, D.N.; Gong, L.F.; Li, B.; Wang, X.W.; et al. Seroprevalence and evolutionary dynamics of genotype 4 hepatitis E virus in Shandong province, China. World J. Gastroenterol. 2014, 20, 7955-7963. [CrossRef] [PubMed]

62. Nakano, T.; Okano, H.; Kobayashi, M.; Ito, K.; Ohmori, S.; Nomura, T.; Kato, H.; Ayada, M.; Nakano, Y.; Akachi, S.; et al. Molecular epidemiology and genetic history of European-type genotype 3 hepatitis E virus indigenized in the central region of Japan. Infect. Genet. Evol. 2012, 12, 1524-1534. [CrossRef] [PubMed]

63. Nakano, T.; Takahashi, K.; Arai, M.; Okano, H.; Kato, H.; Ayada, M.; Okamoto, H.; Mishiro, S. Identification of European-type hepatitis E virus subtype 3e isolates in Japanese wild boars: Molecular tracing of HEV from swine to wild boars. Infect. Genet. Evol. 2013, 18, 287-298. [CrossRef] [PubMed] 
64. Lhomme, S.; Abravanel, F.; Dubois, M.; Chapuy-Regaud, S.; Sandres-Saune, K.; Mansuy, J.M.; Rostaing, L.; Kamar, N.; Izopet, J. Temporal evolution of the distribution of hepatitis E virus genotypes in southwestern France. Infect. Genet. Evol. 2015, 35, 50-55. [CrossRef] [PubMed]

65. Montesano, C.; Giovanetti, M.; Ciotti, M.; Cella, E.; Lo Presti, A.; Grifoni, A.; Zehender, G.; Angeletti, S.; Ciccozzi, M. Hepatitis E virus circulation in Italy: Phylogenetic and evolutionary analysis. Hepat. Mon. 2016, 16, e31951. [CrossRef] [PubMed]

66. Schorn, R.; Hohne, M.; Meerbach, A.; Bossart, W.; Wuthrich, R.P.; Schreier, E.; Muller, N.J.; Fehr, T. Chronic norovirus infection after kidney transplantation: Molecular evidence for immune-driven viral evolution. Clin. Infect. Dis. 2010, 51, 307-314. [CrossRef] [PubMed]

67. Carlsson, B.; Lindberg, A.M.; Rodriguez-Diaz, J.; Hedlund, K.O.; Persson, B.; Svensson, L. Quasispecies dynamics and molecular evolution of human norovirus capsid P region during chronic infection. J. Gen. Virol. 2009, 90, 432-441. [CrossRef] [PubMed]

68. Domingo, E.; Sheldon, J.; Perales, C. Viral quasispecies evolution. Microbiol. Mol. Biol. Rev. 2012, 76, $159-216$. [CrossRef] [PubMed]

69. Todt, D.; Gisa, A.; Radonic, A.; Nitsche, A.; Behrendt, P.; Suneetha, P.V.; Pischke, S.; Bremer, B.; Brown, R.J.; Manns, M.P.; et al. In vivo evidence for ribavirin-induced mutagenesis of the hepatitis E virus genome. Gut 2016, 65, 1733-1743. [CrossRef] [PubMed]

70. Kamar, N.; Izopet, J.; Cintas, P.; Garrouste, C.; Uro-Coste, E.; Cointault, O.; Rostaing, L. Hepatitis E virus-induced neurological symptoms in a kidney-transplant patient with chronic hepatitis. Am. J. Transplant. 2010, 10, 1321-1324. [CrossRef] [PubMed]

71. Lhomme, S.; Garrouste, C.; Kamar, N.; Saune, K.; Abravanel, F.; Mansuy, J.M.; Dubois, M.; Rostaing, L.; Izopet, J. Influence of polyproline region and macro domain genetic heterogeneity on HEV persistence in immunocompromised patients. J. Infect. Dis. 2014, 209, 300-303. [CrossRef] [PubMed]

72. Lhomme, S.; Abravanel, F.; Dubois, M.; Sandres-Saune, K.; Rostaing, L.; Kamar, N.; Izopet, J. Hepatitis E virus quasispecies and the outcome of acute hepatitis E in solid-organ transplant patients. J. Virol. 2012, 86, 10006-10014. [CrossRef] [PubMed]

73. Todt, D.; Walter, S.; Brown, R.J.; Steinmann, E. Mutagenic effects of ribavirin on hepatitis E virus-viral extinction versus selection of fitness-enhancing mutations. Viruses 2016. [CrossRef] [PubMed]

74. Debing, Y.; Emerson, S.U.; Wang, Y.; Pan, Q.; Balzarini, J.; Dallmeier, K.; Neyts, J. Ribavirin inhibits in vitro hepatitis E virus replication through depletion of cellular GTP pools and is moderately synergistic with alpha interferon. Antimicrob. Agents Chemother. 2014, 58, 267-273. [CrossRef] [PubMed]

75. Debing, Y.; Ramiere, C.; Dallmeier, K.; Piorkowski, G.; Trabaud, M.A.; Lebosse, F.; Scholtes, C.; Roche, M.; Legras-Lachuer, C.; de Lamballerie, X.; et al. Hepatitis E virus mutations associated with ribavirin treatment failure result in altered viral fitness and ribavirin sensitivity. J. Hepatol. 2016, 65, 499-508. [CrossRef] [PubMed]

76. Debing, Y.; Gisa, A.; Dallmeier, K.; Pischke, S.; Bremer, B.; Manns, M.; Wedemeyer, H.; Suneetha, P.V.; Neyts, J. A mutation in the hepatitis E virus RNA polymerase promotes its replication and associates with ribavirin treatment failure in organ transplant recipients. Gastroenterology 2014, 147, 1008-1011. [CrossRef] [PubMed]

(C) 2017 by the authors. Licensee MDPI, Basel, Switzerland. This article is an open access article distributed under the terms and conditions of the Creative Commons Attribution (CC BY) license (http:/ / creativecommons.org/licenses/by/4.0/). 